\title{
Comprehensive Evaluation of Smart Grid Development Level Under Electricity Market Layout
}

\author{
Zhe Chen ${ }^{1, *}$, Haiyun $\mathrm{An}^{2}$, and Ze $\mathrm{Sun}^{2}$,Bingcheng $\mathrm{Cen}^{3}, \mathrm{Si}^{\mathrm{Li}^{3}}$ \\ ${ }^{1}$ State Grid JiangSu Electric Power Co.,Ltd.Research Institute, Nanjing,210000, China \\ ${ }^{2}$ State Grid JiangSu Electric Power Co.,Ltd.Research Institute, Nanjing,210000, China \\ ${ }^{2}$ School of Economics and Management, North China Electric Power University, Beijing, 102206, China \\ ${ }^{3}$ State Grid JiangSu Electric Power Co.,Ltd.Research Institute, Nanjing,210000, China \\ ${ }^{3}$ School of Economics and Management, North China Electric Power University, Beijing, 102206, China
}

\begin{abstract}
The smart grid is the latest trend and complex scientific issue in the development of power systems in the world today. With the new round of power system reform and the deregulation of the power market, comprehensive and scientific evaluation of the development level of the smart grid plays an important role in achieving the overall goal of smart grid construction. This paper constructed a comprehensive evaluation index system from the aspects of safety and reliability, economy, intelligence level and sustainability of smart distribution network. Then the comprehensive evaluation model of AHPTOPSIS intelligent distribution network was established. Finally, an empirical study on the development level of smart distribution networks of four power companies in a province was carried out, and corresponding conclusions were drawn.
\end{abstract}

\section{Introduction}

The distribution network is an important part of the power system. It can connect users and transmission and transmission systems, and can provide high reliability and high quality power supply for power users. Therefore, it is the inevitable trend of the development of the power grid to build the traditional power grid into an automation, intelligent and informational advantage, to improve the efficiency of the power grid and to ensure the quality of the power supply. However, the development of smart grid will inevitably affect the current distribution network operation mode and planning structure. With power sector deregulation, investment and construction of smart distribution networks (SDN) will be transformed into a new pattern involving multiple market players. At present, the new round of electricity market reform in China is rapidly advancing, and the investment and operation of the distribution link is gradually changing to the mode of joint participation of many subjects, including the power producers, the users, the load integrators and so on [1]. The comprehensive evaluation of intelligent distribution network is to make a comprehensive judgment on the development level of the current intelligent distribution network, to measure the economic and social benefits of the intelligent distribution network and to guide the development of the future intelligent distribution network. It can provide an important basis for the scientific decision-making of power grid planning, design and operation management personnel.
On the basis of the existing research, this paper studies and puts forward a comprehensive evaluation method for smart grid under the pattern of deregulation power market, scientifically and accurately judging the development level of intelligent distribution network, quantifying the construction effect of intelligent distribution network, and providing practical and effective basis for the construction of intelligent distribution network in the future.

\section{Construction of comprehensive evaluation index system for intelligent distribution network literature references}

Aiming at the plan of intelligent distribution network for electric power market, this paper constructs a comprehensive evaluation index system of intelligent distribution network, which covers four aspects of safety reliability, economy, intelligence and sustainability. There are several level indexes under each level index, and the specific evaluation index system is shown in Table 1.

Table 1 Comprehensive evaluation index system for smart grid development level.

\begin{tabular}{|c|c|c|}
\hline & Primary indicators & $\begin{array}{c}\text { Secondary } \\
\text { indicators }\end{array}$ \\
\hline $\begin{array}{c}\text { Comprehensive } \\
\text { evaluation index system } \\
\text { for smart grid } \\
\text { development level }\end{array}$ & $\begin{array}{c}\text { Safety and reliability } \\
\left(\mathrm{C}_{1}\right)\end{array}$ & $\begin{array}{c}\text { Comprehensive } \\
\text { voltage qualification } \\
\text { rate }\left(\mathrm{C}_{12}\right)\end{array}$ \\
\hline
\end{tabular}

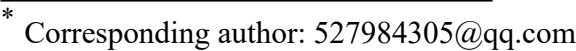




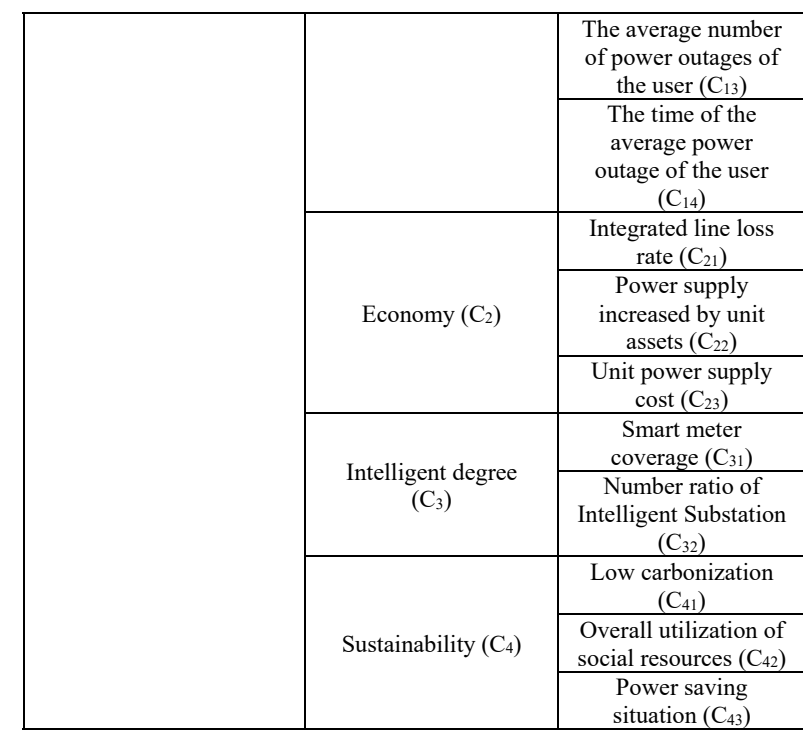

\subsection{Safety and reliability indicators}

Safety refers to the ability to continuously and continuously provide power and power to power users when the power system suddenly has an unexpected situation, that is, the system's ability to avoid power interruptions. The reliability is popular for the stability of the operation of the power system. Generally speaking, the lower the risk is, the higher the reliability is. The reliability is the ability to avoid the risk and the selfhealing ability of the fault.

\subsection{Economic indicators}

The economy is mainly used to reflect the overall income of the distribution network during the operation and operation of the distribution network, as well as the line loss rate and equipment utilization rate. It mainly refers to indicators of economic benefits.

\subsection{Intelligentized degree indicators}

The target of intelligent index system structure is to evaluate the intelligent level of intelligent distribution network. It mainly analyzes and evaluates the intelligentized degree and level of distribution network from the aspects of distribution communication facilities and distribution automation.

\subsection{Sustainability indicators}

Sustainability means that the distribution network can meet the requirements of the social and national sustainable development. From the situation of energy saving and emission reduction in the society and the coordination with the economic and social development in the intelligent distribution network, the quality, low carbonization and coordinated development indicators are put forward.

\section{Determination of indicator weight}

The setting of index weight is an important link in the comprehensive evaluation. Whether the weight of the index is selected is reasonable and directly affects the evaluation result. This paper chooses AHP [2,3] to determine index weights. AHP analyzes the evaluation process of complex systems digitally and systematically, especially for multi-index evaluation decisions [4]. According to the actual situation of the survey, experts are hired to score the indicators, and the indicators are weighted for each indicator layer [5]. According to the scoring situation of relevant experts, the corresponding judgment matrix of each layer is constructed and the weight is calculated. The results of the first level index weight calculation are shown in Table 2.

Table 2 First-level indicator weight calculation.

\begin{tabular}{|c|c|c|c|c|c|}
\hline & $\begin{array}{c}\text { Safety and } \\
\text { reliability }\left(\mathbf{C}_{1}\right)\end{array}$ & Economy $\left(\mathbf{C}_{2}\right)$ & $\begin{array}{c}\text { Intelligent } \\
\text { degree }\left(\mathbf{C}_{3}\right)\end{array}$ & $\begin{array}{c}\text { Sustaina } \\
\text { bility } \\
\left(\mathbf{C}_{4}\right)\end{array}$ & $\begin{array}{c}\text { Weigh } \\
\mathbf{t}\end{array}$ \\
\hline $\begin{array}{c}\text { Safety } \\
\text { and } \\
\text { reliabilit } \\
\mathrm{y}\left(\mathrm{C}_{1}\right)\end{array}$ & 1 & 2 & 2 & 2 & 0.3905 \\
\hline $\begin{array}{c}\text { Econom } \\
\mathrm{y}\left(\mathrm{C}_{2}\right)\end{array}$ & $1 / 2$ & 1 & 2 & 2 & 0.2761 \\
\hline $\begin{array}{c}\text { Intellige } \\
\text { nt degree } \\
\left(\mathrm{C}_{3}\right)\end{array}$ & $1 / 2$ & $1 / 2$ & 1 & 2 & 0.1953 \\
\hline $\begin{array}{c}\text { Sustaina } \\
\text { bility } \\
\left(\mathrm{C}_{4}\right)\end{array}$ & $1 / 2$ & $1 / 2$ & $1 / 2$ & 1 & 0.1381 \\
\hline \multicolumn{5}{|c|}{ Consistency test: $\mathrm{CR}=0.0449<0.1$} & \\
\hline
\end{tabular}

Similarly, according to the above steps, the weights of the secondary indicators corresponding to the firstlevel indicators are calculated as:

$\mathrm{W} 1=(0.33,0.33,0.1404,0.1996), \quad \mathrm{CR}=0.0224<0.1$.It have passed consistency check.

$\mathrm{W} 2=(0.5815,0.3090,0.1095), \mathrm{CR}=0.0033<0.1$. It has passed consistency check.

$\mathrm{W} 3=(0.75,0.25)$

$\mathrm{W} 4=(0.558,0.122,0.32), \quad \mathrm{CR}=0.00915<0.1$. It has passed consistency check.

From this, the final comprehensive weight can be obtained, as shown in Table 3.

Table 3 Weights of comprehensive evaluation indicators for development level of smart distribution network.

\begin{tabular}{|c|c|c|c|c|}
\hline $\begin{array}{c}\text { Primary } \\
\text { indicators }\end{array}$ & Weight & $\begin{array}{l}\text { Secondary } \\
\text { indicators }\end{array}$ & Weight & $\begin{array}{c}\text { Comprehe } \\
\text { nsive } \\
\text { weight }\end{array}$ \\
\hline \multirow{4}{*}{$\begin{array}{l}\text { Safety and } \\
\text { reliability } \\
\qquad\left(C_{1}\right)\end{array}$} & \multirow{4}{*}{0.3905} & $\begin{array}{l}\text { "N-1" pass } \\
\text { rate }\left(\mathrm{C}_{11}\right)\end{array}$ & 0.33 & 0.1289 \\
\hline & & $\begin{array}{l}\text { Comprehensi } \\
\text { ve voltage } \\
\text { qualification } \\
\text { rate }\left(C_{12}\right)\end{array}$ & 0.33 & 0.1289 \\
\hline & & $\begin{array}{l}\text { The average } \\
\text { number of } \\
\text { power } \\
\text { outages of } \\
\text { the user }\left(\mathrm{C}_{13}\right)\end{array}$ & 0.1404 & 0.0548 \\
\hline & & $\begin{array}{l}\text { The time of } \\
\text { the average } \\
\text { power outage } \\
\text { of the user } \\
\left(\mathrm{C}_{14}\right)\end{array}$ & 0.1996 & 0.0779 \\
\hline \multirow{3}{*}{$\begin{array}{l}\text { Economy } \\
\left(\mathrm{C}_{2}\right)\end{array}$} & \multirow{3}{*}{0.2761} & $\begin{array}{c}\text { Integrated } \\
\text { line loss rate } \\
\left(\mathrm{C}_{21}\right)\end{array}$ & 0.5815 & 0.1606 \\
\hline & & $\begin{array}{l}\text { Power supply } \\
\text { increased by } \\
\text { unit assets } \\
\left(\mathrm{C}_{22}\right)\end{array}$ & 0.3090 & 0.0853 \\
\hline & & $\begin{array}{l}\text { Unit power } \\
\text { supply cost }\end{array}$ & 0.1095 & 0.0302 \\
\hline
\end{tabular}




\begin{tabular}{|c|c|c|c|c|}
\hline & & $\left(\mathrm{C}_{23}\right)$ & & \\
\hline \multirow{7}{*}{$\begin{array}{c}\text { Intelligent } \\
\text { degree }\left(\mathrm{C}_{3}\right)\end{array}$} & \multirow{2}{*}{0.1953} & $\begin{array}{c}\text { Smart meter } \\
\text { coverage } \\
\left(\mathrm{C}_{31}\right)\end{array}$ & 0.75 & 0.1465 \\
\cline { 3 - 5 } & $\begin{array}{c}\text { Number ratio } \\
\text { of Intelligent } \\
\text { Substation } \\
\left(\mathrm{C}_{32}\right)\end{array}$ & 0.25 & 0.0488 \\
\hline \multirow{5}{*}{$\begin{array}{c}\text { Sustainability } \\
\left(\mathrm{C}_{4}\right)\end{array}$} & \multirow{2}{*}{0.1381} & $\begin{array}{c}\text { Low } \\
\text { carbonization } \\
\left(\mathrm{C}_{41}\right)\end{array}$ & 0.558 & 0.0771 \\
\cline { 3 - 5 } & $\begin{array}{c}\text { Overall } \\
\text { utilization of } \\
\text { social } \\
\text { resources } \\
\left(\mathrm{C}_{42}\right)\end{array}$ & 0.122 & 0.0168 \\
\cline { 3 - 5 } & $\begin{array}{c}\text { Power saving } \\
\text { situation } \\
\left(\mathrm{C}_{43}\right)\end{array}$ & 0.32 & 0.0442 \\
\hline
\end{tabular}

\section{Comprehensive evaluation method for development level of AHP-TOPSIS smart distribution network}

\subsection{Basic principles of the TOPSIS method}

The TOPSIS method[6], also known as the superior and inferior solution distance method, is a sorting method that approximates the ideal solution. It only requires that each factor has monotonicity. It sorts the alternatives by detecting the evaluation object and the optimal solution and the worst solution distance. If an alternative is closest to the optimal solution and farthest from the worst solution, it is the optimal solution. The TOPSIS method is a commonly used effective method in multiobjective decision analysis. The advantage is that it can be formed directly for reference decision information [7]

\subsection{AHP-TOPSIS method comprehensive evaluation steps}

Based on the basic principles and characteristics of AHP and TOPSIS, the AHP method is too dependent on the subjective experience of the decision-makers and cannot directly form a reference decision information. While the TOPSIS method is difficult to determine the weight of the index under the condition of multi factor analysis, this paper evaluates the intelligent distribution network by combining two methods. The specific steps and processes are as follows:

(1) According to the established evaluation index system, we use AHP to determine the weight of each index.

(2) Construct an initial evaluation matrix. According to the composition characteristics of the evaluation objects, the index set $X=\left\{x_{1}, x_{2}, \ldots, x_{n}\right\}$ of the $M$ samples is composed of the sample set A. And establish an initial evaluation matrix in order: $A=\left(x_{i j}\right)_{m \times n}$.

(3) Standardization of decision matrices. Different indicators cannot be directly compared because of differences in dimension and dimension units. In order to eliminate the dimension between indicators, it is necessary to standardize the indicators.

(4) Establish a weighted standardized decision matrix. The weighted normalization decision matrix can be obtained by multiplying the column vector of the normalized decision matrix $\mathrm{Z}$ by the integrated weight of the index in the corresponding AHP method.

(5) Closeness calculation. The close degree reflects the degree of the sample's indexes close to the optimal solution. First, the optimal solution and the worst solution of the weighted standardized decision matrix should be found. The optimal solution for the income index set $J_{1}$ is the maximum value of the row vector, the worst solution is the minimum value of the row vector, and the value of the consumptive index set $\mathrm{J}_{2}$ is the opposite. There are:

$$
\begin{aligned}
& r_{j}^{+}=\left\{\left(\max _{1 \leq j \leq m} r_{i j} \mid j \in J_{1}\right),\left(\min _{1 \leq j \leq m} r_{i j} \mid j \in J_{2}\right) i=1,2, \ldots, m\right\} \\
& r_{j}^{-}=\left\{\left(\min _{1 \leq j \leq m} r_{i j} \mid j \in J_{1}\right),\left(\max _{1 \leq j \leq m} r_{i j} \mid j \in J_{2}\right) i=1,2, \ldots, m\right\}
\end{aligned}
$$

Then, the Euclidean distance[8] is obtained as follows:

$$
\begin{gathered}
d_{1}^{+}=\sqrt{\sum_{j=1}^{n}\left(r_{i j}-r_{j}^{+}\right)^{2}}(i=1,2, \ldots, m) \\
d_{1}^{-}=\sqrt{\sum_{j=1}^{n}\left(r_{i j}-r_{j}^{-}\right)^{2}}(i=1,2, \ldots, m)
\end{gathered}
$$

Relative proximity can be obtained according to the following calculation methods:

$$
C_{i}=\frac{d_{i}^{-}}{d_{i}^{+}+d_{i}^{-}}(i=1,2, \ldots, m)
$$

$\mathrm{C}_{\mathrm{i}}$ indicates the closeness. When the sample is the optimal solution, $\mathrm{Ci}=1$, when the sample is the worst solution, $\mathrm{C}_{\mathrm{i}}=0$; the closer to the optimal solution, the more the $\mathrm{C}_{\mathrm{i}}$ approaches 1 , and conversely, the closer to the worst solution, the more $\mathrm{C}_{\mathrm{i}}$ the closer to 0 .

\section{Case analysis}

This paper selects four municipal-level power companies in a certain province (recorded as A, B, C, and D respectively), and collects and sorts out relevant data. Among them, the qualitative index data is based on the expert scoring method, and 10 experts are selected for scoring, and the average value is used as the index data. Then standardize the decision data and calculate the weighted normalization decision matrix as: 


$$
R=\left[\begin{array}{llll}
0.0605 & 0.0591 & 0.0683 & 0.0692 \\
0.0643 & 0.0646 & 0.0647 & 0.0642 \\
0.0278 & 0.0217 & 0.0327 & 0.0264 \\
0.0439 & 0.0390 & 0.0368 & 0.0356 \\
0.0714 & 0.0839 & 0.0870 & 0.0779 \\
0.0387 & 0.0529 & 0.0361 & 0.0409 \\
0.0159 & 0.0179 & 0.0126 & 0.0135 \\
0.0809 & 0.0609 & 0.0611 & 0.0864 \\
0.0122 & 0.0278 & 0.0240 & 0.0297 \\
0.0373 & 0.0395 & 0.0382 & 0.0391 \\
0.0080 & 0.0085 & 0.0089 & 0.0082 \\
0.0223 & 0.0213 & 0.0228 & 0.0220
\end{array}\right]
$$

Therefore, the optimal solution is:

$r_{j}^{+}=[0.0692,0.0647,0.0217,0.0356,0.0714,0.0529,0.0$ $126,0.0864,0.0297,0.0395,0.0089,0.0228]$

The worst solution is:

$r_{j}^{-}=[0.0591,0 ., 0642,0.0327,0.0439,0.0870,0.0361,0$. $0179,0.0609,0.0122,0.0373,0.0080,0.0213]$

The European space distances of the four city-level power company index levels are calculated respectively, and the calculated Euclidean space distance is shown in Table 4.

Table 4 Euclidean Space Distance.

\begin{tabular}{|c|c|c|}
\hline $\begin{array}{c}\text { Electricity } \\
\text { company }\end{array}$ & $\begin{array}{c}\text { Distance between } \\
\text { the optimal solution }\end{array}$ & $\begin{array}{c}\text { Distance between } \\
\text { the worst solution }\end{array}$ \\
\hline A & 0.0272 & 0.0261 \\
\hline B & 0.0309 & 0.0262 \\
\hline C & 0.0363 & 0.0175 \\
\hline D & 0.0145 & 0.0360 \\
\hline
\end{tabular}

According to formula 5, the closeness of the solution to the optimal solution is shown in Table 5 .

Table 5 Closeness.

\begin{tabular}{|c|c|c|}
\hline $\begin{array}{c}\text { Electricity } \\
\text { company }\end{array}$ & Closeness & Evaluation ranking \\
\hline $\mathrm{A}$ & 0.4902 & 2 \\
\hline $\mathrm{B}$ & 0.4591 & 3 \\
\hline $\mathrm{C}$ & 0.3250 & 4 \\
\hline $\mathrm{D}$ & 0.7128 & 1 \\
\hline
\end{tabular}

According to the above calculation, the relative closeness of the four power companies is sorted. The result is: $\mathrm{D}>\mathrm{A}>\mathrm{B}>\mathrm{C}$. The greater the relative closeness is, the better the comprehensive evaluation of the smart distribution network is. In other words, the smart grid of $\mathrm{D}$ has the highest development level, the A level of power grid and the B level of power grid are basically flat, and the development level of power grid $\mathrm{C}$ is the lowest.

\section{Summary}

Aiming at the diversified participation characteristics of investment in power distribution field under the background of China's power market reform, this paper studies and proposes a comprehensive evaluation system and method that can be applied to the planning decision of smart distribution network under the new situation. The factors related to the intelligent level evaluation of the regional transmission and distribution network in China were analyzed, and the comprehensive evaluation index system of intelligent distribution network was constructed from four dimensions of the security reliability, economy, intelligence level and sustainability of the intelligent distribution network, and the AHPTOPSIS evaluation model was selected for comprehensive evaluation. Finally, according to the established index system and evaluation model, the 4 electric power companies in a province were analyzed and the corresponding evaluation results were obtained. It is proved that the model has a certain scientific applicability.

\section{References}

1. H.A. Hejazi, A.R. Araghi, B. Vahidi B, et al. J. IEEE T. on Power Syst. 28, 1170(2013).

2. T.L.Saaty, The Analytic Hierarchy Process. M .New York:McGraw-Hill Company.(1980).

3. Zhipeng Y, Ming Z. J. Silicon Valley. 21,112(2010).

4. Niantao X, Guochen Z, Jian C, et al. Res. Environ. Sci. 27, 99(2014).

5. Yuzhen J, Kaijun W, Mingxia Z, et al. J. Anhui Agric. Sci. 40, 6063(2012).

6. Xinghua C .D. East China Normal Univ.(2014).

7. Qiaofeng F. J. Xi'an Univ. Sci. Technol. 28, 190(2008).

8. Guoquan W, Guangwen F. J. Environ Sci and Man. 36, 22(2011). 